\title{
Lean engineering in the design process: An industrial application
}

\author{
Toufik Boudouh*, and Samuel Gomes \\ ICB UMR 6303, CNRS, Univ. Bourgogne Franche-Comté, UTBM, Belfort, France
}

\begin{abstract}
The objective of this paper is to present a methodology used to streamline the product development process by introducing Lean Engineering concepts. We are interested specifically in routine design which represents in some companies more than $80 \%$ of the design activity. A project management model was developed and implemented in a PLM tool. This allows faster initiation of projects in which project planning is automatically performed. Hence, non-added value tasks in project planning were identified and reduced.
\end{abstract}

\section{Introduction}

To increase their competitiveness, companies are required to increase the turnover of their products. They should continuously develop attractive new products efficiently in order to increase sales volume and ensure sustainability in globalized markets. Streamline of routine engineering processes becomes necessary to improve quality and productivity in design and will allow more time to develop new products.

We must reduce the length of the non-added value tasks to free up time for innovative projects. Engineering design is a source of competitive advantage for manufacturing companies. Reducing the development time is a key factor in the successful completion of the product development process in a time based competition context. During the last decades, the design process is subject to new methodologies and tools to make it more and more efficient. As what was done in manufacturing, lean engineering techniques were introduced into the design process. The objective is to reduce the non-added value tasks of the design process.

Design is an information intensive activity. Because of the complex information dependencies that exist between design tasks, we cannot perform the design process as a once-through procedure. Therefore, iterations are necessary to resolve design problems. These iterations are often seen as non-added value tasks. Understanding and controlling iterations can improve the design process, and reducing them would have positive effects for the product development cycle time [1]. The purpose of lean engineering is to introduce new methodologies helping the designer approach the ideal design solution as rapidly as possible.

In this paper, we describe a project management methodology, implemented using a PLM system. The objective of this methodology is to streamline the product development process by introducing Lean Engineering techniques in project management. We are interested

\footnotetext{
*Corresponding author: toufik.boudouh@utbm.fr
} 
specifically in routine design which represents in some companies more than $80 \%$ of the design activity [2-3]. Thus, reducing these tasks will allow more time for innovative design. The methodology was applied in a SME in which two types of projects where identified: long projects and short projects. For each type, a project management model was developed and implemented in the PLM tool. This allows faster initiation of projects in which project planning is automatically performed. Hence, non-added value tasks in project planning were identified and reduced. The use of the PLM tool allows also taking into account the manufacturing issues since the design phase.

\section{Methodology}

The use of a PLM (Product Lifecycle Management) tool for coupled with a streamlined design methodology, simplifies the achievement of the project, document archiving, and improves communication between actors involved in the project and product lifecycle. ACSP is an organizational tool for collaborative project management providing these features. It was developed at the University of Technology of Belfort-Montbéliard, France. This tool provides a software environment for distributed collaborative design [3], centralizing different data related to the design project of the product and its manufacturing process. Positioned in the context of concurrent engineering [4], the goal of such a tool is to support the design process in terms of cooperation between the different actors of the design: engineers, technicians, decision makers, users, manufacturing operators, etc.... It also allows a better definition of the project (planning, project team definition, workload rates, etc...), and a better visualization of tasks to be performed by each project member. In addition to the basic function of document management and communication specific to PLM systems, the tool must allow to manage the product development process through considering interrelated tasks. Standardization of some project templates, grouping already predefined tasks (according to various project models in the company), the standardization of the duration of tasks, the standardization of documents and intelligent inter-connections of tasks, saves considerable time in developing the project plan. Visualization of the workload profile of each project member also allows to create realistic schedule estimates, taking into account the implication of these members in other projects. Therefore, from standard projects, the creation of a new project including project scheduling is facilitated by a semiautomatic formatting of the project.

\section{Industrial case study and application}

Our methodology was tested and implemented in a SME company. Despite the presence of a design office and a process planning office, we noticed in the beginning of the project the absence of a standard design methodology. There is no formal method to capture and reuse the knowledge gained at the completion of each project. We have also identified several barriers to the integration of a PLM tool in such a company. These barriers range from the employees' resistance to change, to the number of ongoing projects as well as the amount of data to be added to the PLM by each project member. As actors in the implementation of the PLM tool, we felt it necessary to provide a clear and easily usable tool. It was also necessary to go through several steps before a full deployment of the tool.

The first step in PLM implementation was to map the current way of working by listing all the tasks and deliverables of any project. Indeed, the company has no standard design procedure for its projects and project activities can be performed in any order. In this case, information may be lost and the communication is poor among the different project members. Once the tasks identified, the next step was to define standard deliverables, using a model 
that should be shared by all the actors involved in the different product development projects. A standard schedule of the project tasks is necessary to get homogenous and streamlined project information. A Gantt chart was then constructed to organize these tasks. Each task was assigned a standard average duration. Using the information gathered, it was possible to construct and setup project tasks in the PLM tool (ACSP).

The main characteristics of the studied company are the number, diversity, and complexity of projects:

- 150 projects are undertaken simultaneously.

- Project durations are very different from one project to another.

- Project complexity is variable from one project to another (from simple to complex).

For these considerations, during the creation of the WBS (Work Breakdown Structure) for the identification of standard activities, two project templates have been created: short project model and long project model.

\subsection{Long project template}

The long project template is a project model including all phases necessary for the proper achievement of a project, from pre-study to concept validation (Figure 1). In this model, market and technical environments are unknown. So, this will require further research activities, such as functional analysis or marketing analysis. Long projects involve all the departments of the company from the sales department to the production shop floor. Generally, long projects are mainly initiated by the innovation department, or after a comparative study, or for alignment to standards.

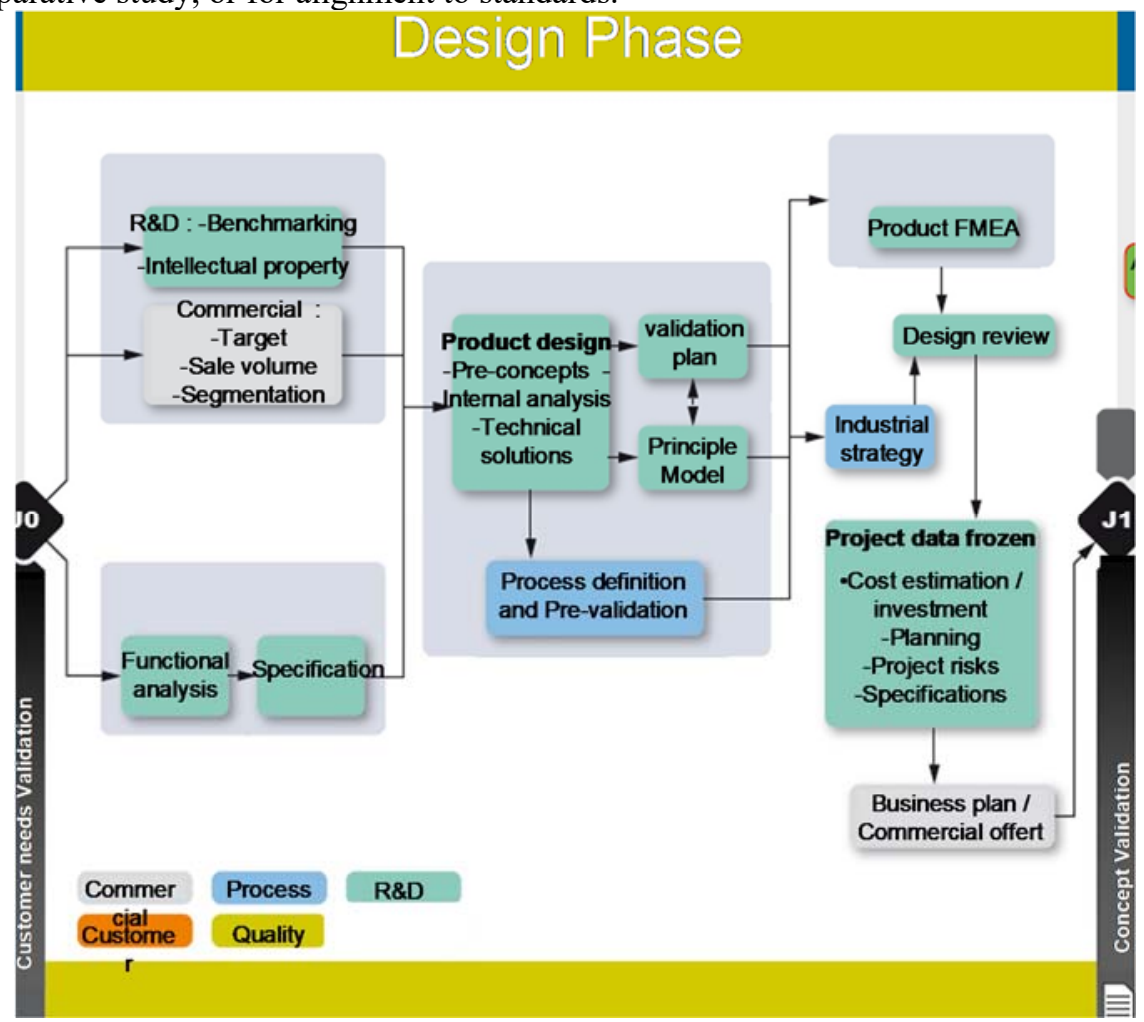

Fig. 1. Long project template: design phase. 


\subsection{Short project template}

The short project template includes various types of short projects. These projects could be classified into two categories. Projects with lower risks in the design phase where the risks in terms of reliability and consistency are controlled. The technical solution is generally obvious; the validation of this solution is performed by evaluation of its cost, time and performance using analogy or the experience of project members. Projects with strong risks in the design phase, where design risks are vague and require further investigations using product and process FMEA. The difference with a long project is characterized by a better mastered environment because it's much more known, so a phase of information research much more short and simple (Figure 2). Reflection on the choice of a path to high or low risk is determined in advance by experts and managers. In case of doubt, the project risk is considered as high and a feasibility study is performed including a product and process FMEA. In the case of short projects with low risk, a solution is evaluated by various experts involved in the product development and the management relying on the company's knowledge and experience. Capitalization of this knowledge is then necessary to facilitate and accelerate the evaluation of future projects. Generally, short projects consist of component modifications, or creating a product variant on the basis of a known model in order to respond to a customer demand. These tasks, which are routine task, mainly occupy $60 \%$ of the company's studied projects. Thus, in a short project, the customer quotation is delivered much more quickly than in a long project. Reactivity is the most important factor for the customer.

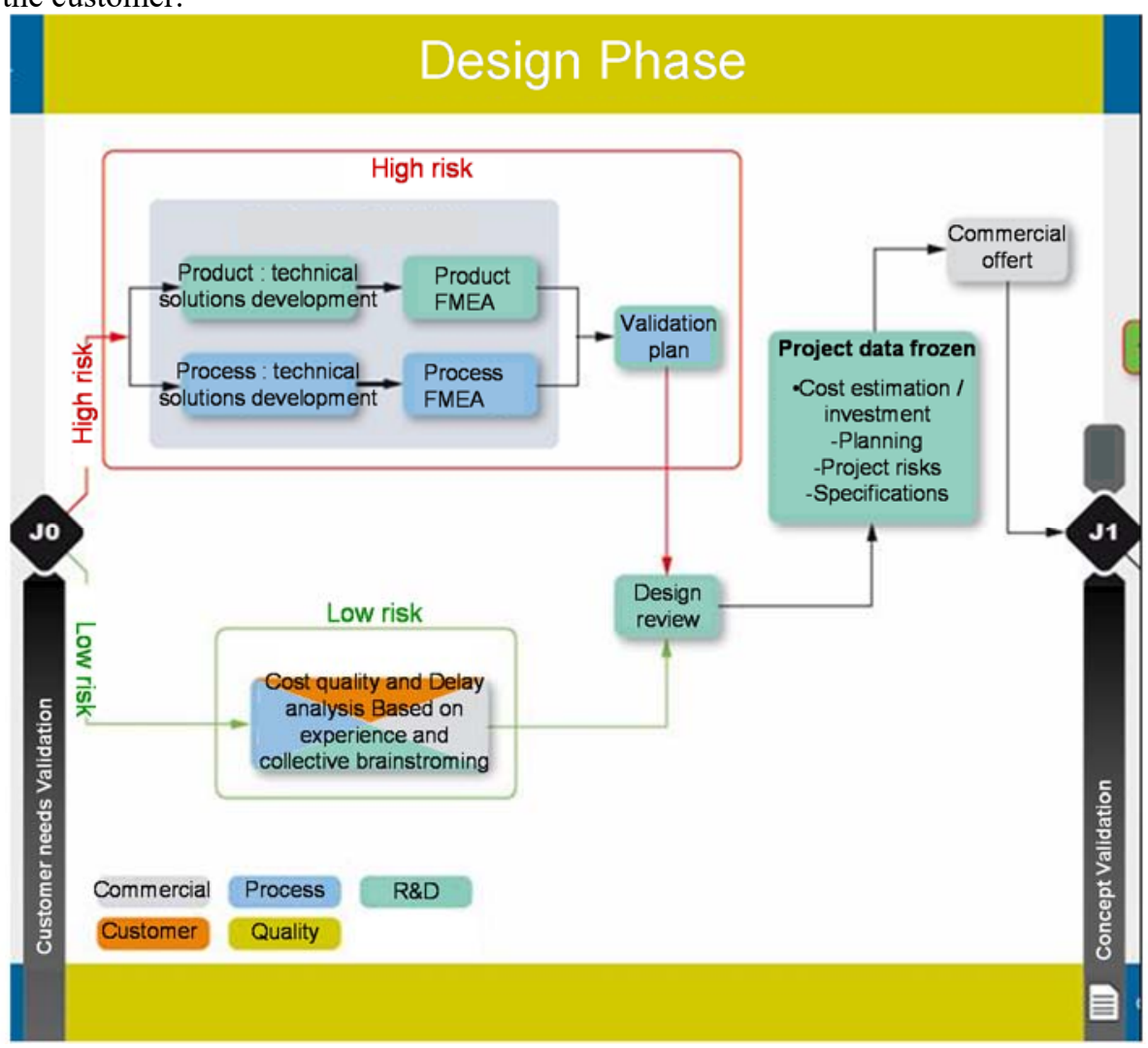

Fig. 2. Short project template: design phase. 


\subsection{Automating the implementation of projects}

A module for creating projects allows the quick and easy initiation of projects. Based on performance indicators which allow knowledge capitalization of the company, the project templates (long and short) are continuously optimized. This adjusts the standard duration of tasks, the actual workload, and the management of standard documents.

This automated implementation allows having a look ahead of the whole project, thereby improving the timeliness, the organizational quality of the project, and also being more reactive to customer needs in terms of quality, cost, and time.

Moreover, by using a module for project duplication, projects of different lengths can be created from standard project through automated coefficients, thus setting the length of the tasks automatically for new projects.

Thus, the user avoids performing an update of the duration of each task of a new project and can extract quickly a schedule of the project (Figure 3).

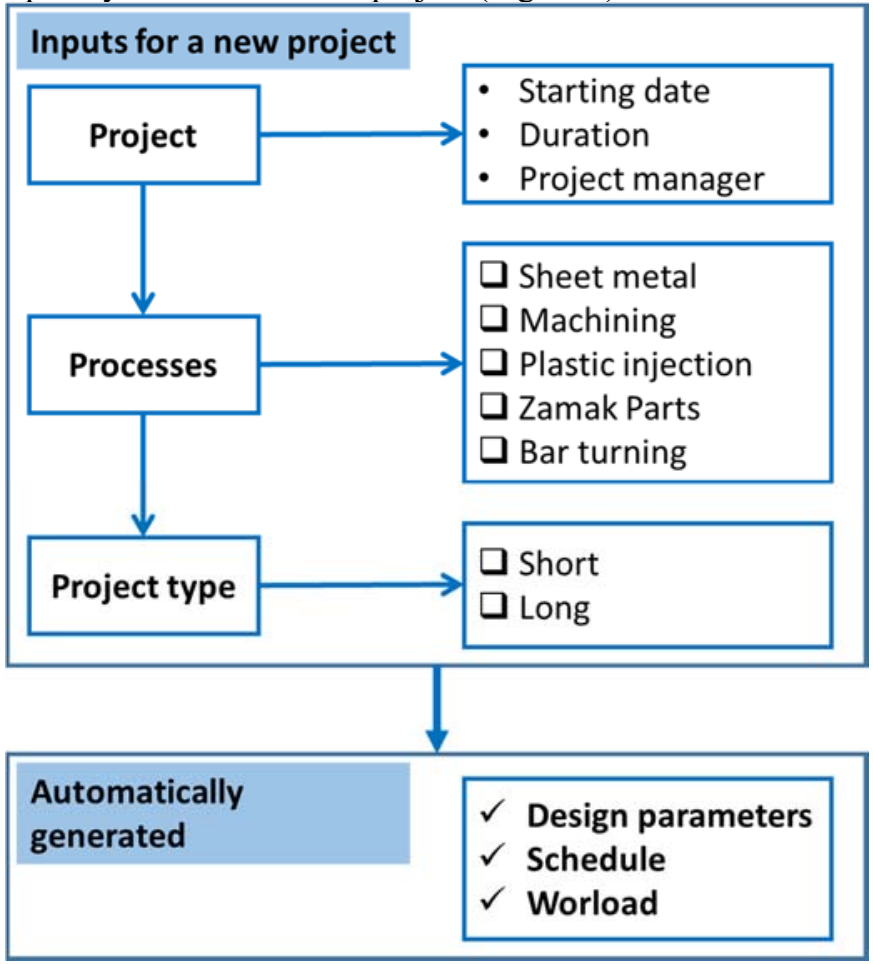

Fig. 3. Initiation of a new project.

\section{Conclusion}

Lean engineering deals with the reduction of waste in the product development process. Waste is considered as any task without a significant added value. Reducing these tasks will free up valuable time that could be used for innovation.

Lean engineering concepts should be first applied for routine design which account for nearly $80 \%$ of the time in a design office.

We proposed in this paper to add semi-automated project management functionalities in a PLM to generate significant time savings in the implementation of new projects.

Resource management and automatic verification of workloads allow for project initiation with realistic durations and avoid resource overload. 
Once the PLM tool is set up in the company and used by all team project members, the prospects for a highly productive engineering design can be deployed in the product development process.

Indeed, after company knowledge capitalization by coupling the ACSP tool with KBE (Knowledge Based Engineering) techniques [5], it becomes possible to automatically generate engineering applications. The goal being always the reduction of the time dedicated to routine tasks.

\section{References}

1. T.R. Browning, IEEE Trans. Eng. Manag., 48 (2001)

2. T. Boudouh, C. Vernier, N. Lebaal, S. Gomes, 14th International DSM Conference, Kyoto, Japan, (2012)

3. S. Gomes, D. Monticolo, V. Hilaire, M. Mahdjoub, Int. J. Prod. Lifecy. Mgt, 2 (2007)

4. G. Sohlenius, Ann. CIRP, 41 (1992)

5. S. Gomes, P. Serrafero, D. Monticolo, B. Eynard, International Conference in Product Lifecycle Management, Lyon, (2005) 